\title{
Skin-Adhesive Tape versus Interrupted_Suture in Episiotomy Skin Repair: Randomized Control Trial
}

\author{
Ahmed Sherif*, Maged El-Shourbagy \\ Department of Obstetrics \& Gynecology, Ain-Shams University, Cairo, Egypt \\ Email: *ahmedgyna@yahoo.com
}

How to cite this paper: Sherif, A. and El-Shourbagy, M. (2020) Skin-Adhesive Tape versus Interrupted_Suture in Episiotomy Skin Repair: Randomized Control Trial. Open Journal of Obstetrics and Gynecology, 10, 254-263. https://doi.org/10.4236/ojog.2020.1020022

Received: November 20, 2019

Accepted: February 11, 2020

Published: February 14, 2020

Copyright $\odot 2020$ by author(s) and Scientific Research Publishing Inc. This work is licensed under the Creative Commons Attribution International License (CC BY 4.0).

http://creativecommons.org/licenses/by/4.0/

(c) (i) Open Access

\begin{abstract}
Introduction: The ideal method for perineal repair should be quick, easy to perform and preferably, with minimal pain. Aim: To compare skin adhesive tape and interrupted absorbable subcuticular suture for episiotomy repair after birth as regard postoperative pain, skin closure time and wound infection. Design: Prospective double-blinded randomized controlled trial. Methods: Three-hundred qualified patients were equally distributed between two groups. Group 1 underwent skin repair with skin adhesive tape, while group 2 underwent the currently traditional method for perineal repair by interrupted suture. Pain was evaluated at 2, 4, 6 and 12 hours after birth then daily until one week using Wong-Baker faces pain rating scale with verbal expression for pain intensity as primary outcome. Skin closure time and wound infection were also evaluated as secondary outcomes. Results: Statistically significant difference in pain was found at 4 and 6 hours, and 3, 4, 5 and 7 days after perineal repair in favor of the adhesive tape group $(\mathrm{p}=0.04$ and 0.02 respectively) ( $\mathrm{p}=0.002,0.002,0.003$ and 0.001 respectively). No statistically significant difference was found in skin closure time between both groups, and no cases of wound infection occurred in both groups $(p=0.3)$. Conclusion: Skin adhesive tape may be superior to skin suturing in decreasing pain resulting from perineal repair after birth; however, further studies are needed to assess long-term effects, calculate costs and accurately measure patients' satisfaction, which were not addressed in this study.
\end{abstract}

\section{Keywords}

Skin Adhesive Tape, Interrupted Sutures, Episiotomy Skin Repair, Pain

\section{Introduction}

Episiotomy is the commonest operating procedure performed by obstetricians in 
their lifetime. In hospital deliveries, episiotomy became the rule rather than the exception [1], especially in Egypt as the prevalence of female genital cutting is unfortunately high [2], which increases the risk of genital tract laceration [3].

The ideal method for perineal repair should be quick, easy to perform and preferably, with minimal pain and dyspareunia during the puerperium [4]. The closure technique which avoids the need to puncture the skin, will avoid introduction of a foreign body, and consequently inflammation and scarring will be reduced [5].

A systemic review conducted in 2010, has revealed that non-suturing of perineal skin alone in first and second degree tears and episiotomies may reduce pain and dyspareunia in the puerperium but may lead to increased risk of wound gaping [6], which is important for primary skin healing and avoidance of infection [7].

Lazar et al. [8], examined wound healing using the adhesive skin tape, Surgical Skin system and concluded that there was significantly less erythema and edema, in addition to, improved cosmoses as compared to the traditional skin closure using an absorbable interrupted suture technique.

The aim of current work is to compare two different techniques of skin closure in perineal repair after vaginal delivery; the first technique is skin adhesive tape as a new alternative to leaving the skin unsutured-to avoid the problem of wound gaping associated with such technique-and the second technique is absorbable interrupted suture technique as regard postoperative pain (primary outcome), skin closure time and wound infection (secondary outcome).

\section{Patients \& Methods}

This prospective double-blinded randomized controlled trial (parallel assignment) was conducted in a big private hospital from January 2017 to December 2019. Randomization was done using a computer generated randomization table using Research Randomizer Version 4.0 software in a 1:1 ratio, using a case code written in a piece of paper and put in an opaque concealed enveloped which carried the case number. The letter A referred to women randomized to skin repair with adhesive tape and letter $\mathrm{S}$ refers to women randomized to skin repair with suture. Allocation concealment was ensured as the service did not release the randomization code until the patient was recruited into the trial, which took place after all baseline measurements have been completed.

The Ethical Committee of the hospital approved this study. All patients willing to participate signed an informed consent immediately after admission to labor ward and were subjected to detailed history taking (personal, menstrual, obstetric \& past history), examination (general, abdominal \& local pelvic examination), ultrasonography and laboratory investigations (C.B.C, Rh, blood grouping and albumin in urine) to select the patients fulfilling the inclusion criteria which are: age 18 or more, primipara, having spontaneous natural birth and episiotomy. Women with local infection or lesions, maternal disease interfering 
with wound healing e.g. Diabetes mellitus, immunosuppression and coagulopathy, known hypersensitivity to steri-strips were excluded. Group 1 underwent skin repair with skin adhesive tape, while group 2 underwent the interrupted absorbable suture technique.

\section{Surgical procedure:}

Preparation for natural birth:

At the end of second-stage of labor, when the perineum begins to distend, the fetal scalp was seen through the separating labia, and bearing-down reflexes started participants were placed in dorsal lithotomy position for better exposure. Vulvar and perineal cleansing was done by povidone iodine $10 \%$ solution.

Episiotomy:

When the vulvovaginal opening is dilated by the largest fetal head diameter (crowning), the perineum was infiltrated by $1 \%$ lidocaine and a medio-lateral episiotomy was done, scissors were positioned at 7 o'clock, and the incision was extended 3 to $4 \mathrm{~cm}$ toward the ipsi-lateral ischial tuberosity (in cases needing episiotomy).

Perineal Repair following Delivery:

As soon as birth was completed the initial assessment of episiotomy wound was performed gently to classify the perineal trauma caused by episiotomy. Third and fourth degree trauma excluded from the research. After full explanation of the procedure to the mother, she was placed in a position allowing good visualization, vulval/perineum washed and draped with sterile drapes. The vagina inspected and the apex of the episiotomy identified. If needed, another infiltration with $1 \%$ Lignocaine up to a total of $20 \mathrm{mls}$ to the area. A gauze tampon was inserted into the upper vagina, above the trauma to absorb any bleeding from the uterus, which may obscure the field of operation. The vagina was sutured after good visualization of the apex of the wound starting approximately $0.5 \mathrm{~cm}$ above this point and the vaginal wall was repaired using a continuous non-locking stitch continued to the hymenal remnants, then the needle placed behind the hymenal remnants and emerge in the center of the perineal muscle. After checking the depth of trauma, the perineal muscles were repaired in one or two layers with the same continuous stitch leaving no dead space [9].

The time started to be calculated and cases were distributed as follows:

Group 1 Steri-strips $\left(3 \mathrm{M}^{\mathrm{TM}}\right.$ Steri-Strip ${ }^{\mathrm{TM}} 6 \mathrm{~mm} \times 100 \mathrm{~mm}$; reinforced skin closure) applied perpendicular to the wound by lifting the skin edges up with gloved finger, placing the first $1 / 2$ of steri-strip tape with 90 degree angle over the first edge, pressing firmly, ensure edges are met together then placing the other half and press firmly. 3 to 4 tapes placed with approximately $0.5 \mathrm{~cm}$ spaces in between.

Group 2 polyglactin 910 (Vicryl Rapid ${ }^{\mathrm{TM}} 2-0$ ) was used as follow: After repairing the muscular layer the $t$ interrupted absorbable suture technique.

The procedure timing stopped for both groups and recorded.

Outcome measures: 
As the local injectable lidocaine become effective within 5 - 10 minutes, and lasts on average from 45 minutes to 1 hour [10], all participants were evaluated for pain immediately after procedure, 2, 6 and 12 hours after delivery, using Wong-Baker faces pain rating scale with verbal expression for pain intensity [11].

Before discharge, after brief explanation, all women participating were asked to complete a home daily postnatal pain score chart of 7 days duration using the same scale. When the results of the first 7 days were recorded, the patients were asked to return to the hospital for second evaluation. The patients were able to contact hospital by visit or telephone all through the 7 days, and the needs for medical advice were recorded (Figure 1).

In the second visit (seven to ten days after birth) evaluations of the wound were done using REEDA score (redness, edema, ecchymosis, discharge and wound approximation) [12], and the patients were asked to complete a second questionnaire, evaluating their satisfaction depending on pain intensity during daily activities using the same pain scale.

\section{Sample Size Justification}

The required sample size has been calculated using the $\mathrm{G}^{\star}$ Power Software (Universität Düsseldorf, Germany).

The primary outcome measure is the difference between the two groups as regards the pain. The secondary outcome measures were the time of the procedure, wound infection and pain affecting patient's satisfaction.

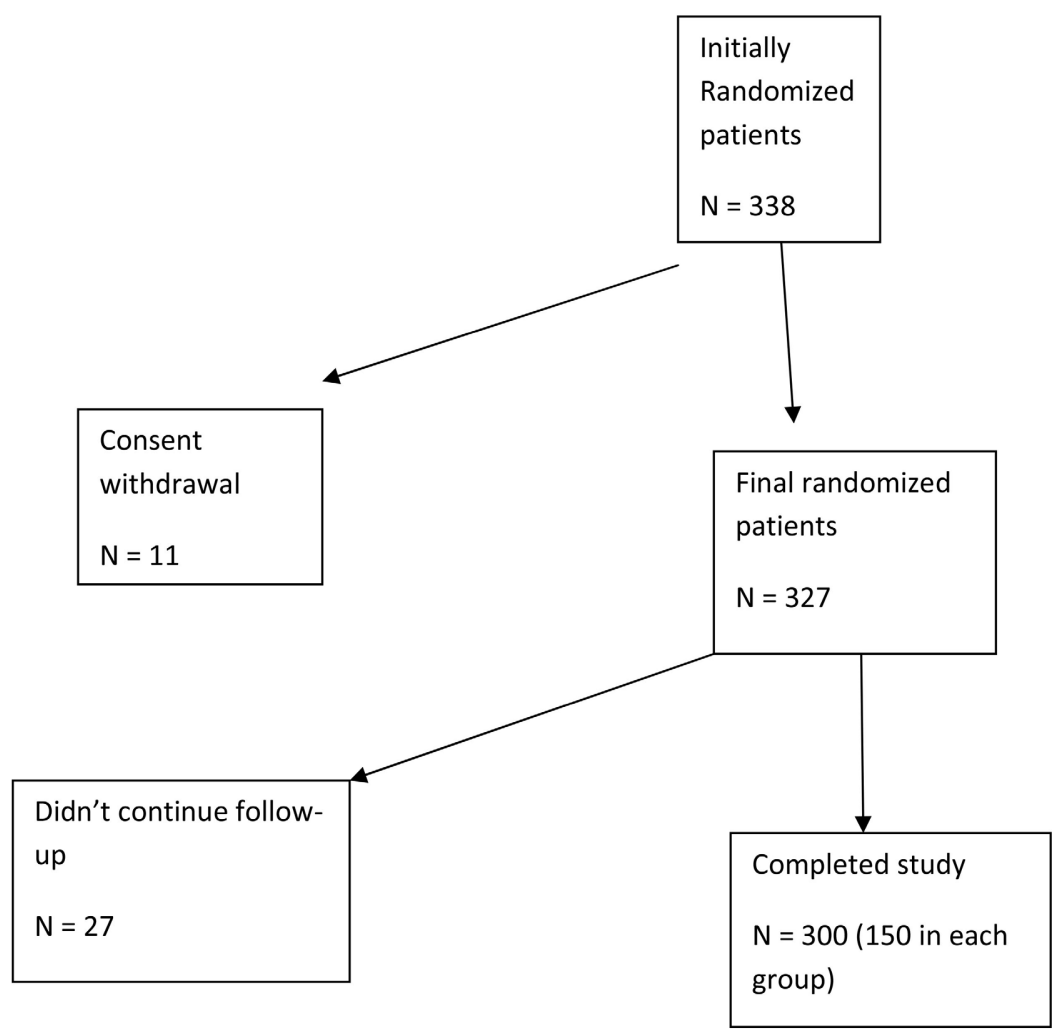

Figure 1. Consort flow chart. 
Since there is currently no adequate information regarding the expected difference in the outcome measures between the two interventions under investigation, the current exploratory study targeted an effect size that would be clinically relevant.

So, it was estimated that a total sample size of 300 patients equally randomized into either study group ( $\mathrm{n}=150$ per group) would achieve a power of $95 \%$. We estimated that between $10 \%$ and $15 \%$ of cases will be lost to follow-up so 338 cases were initially included.

\section{Statistical analysis:}

Data were collected, tabulated, then analyzed using IBM Corp., Armonk, NY).

Normally distributed numerical data was presented as mean and SD, and skewed data as median and interquartile range. Qualitative data was presented as number and percentage. Comparison of normally distributed numerical data was done using the unpaired student $t$ test. Skewed data was compared using Mann-Whitney U test. Categorical data was compared using chi-squared test or Fisher's exact test, when appropriate. A two-sided p-value $<0.05$ was considered statistically significant.

\section{Results}

The demographic data in the form of median and range of age of cases in years, gestational age at birth in weeks, the number of cases having episiotomy and the number of cases having first or second degree perineal tear in both groups are shown in Table 1.

As regards the time of skin closure there was an insignificant difference between both groups $(p=0.30)$ as the range was between 1 and 5 minutes in the suture group with a median interquartile range of $3(2-4)$ as compared to a range between 1 and 10 minutes with a median interquartile range of $3(2-4)$.

Pain was less in the adhesive tape group at 4 and 6 hours $(\mathrm{p}<0.05)$ (Table 2), and 3, 4, 5 and 7 days after perineal repair $(\mathrm{p}<0.01)$ (Table 3$)$. Eight cases

Table 1. Difference between interrupted suture closure and adhesive strip group regarding the demographic data (age, gestational age at delivery, number of cases with episiotomy and number of cases with $1^{\text {st }}$ and $2^{\text {nd }}$ degree perineal tear.

\begin{tabular}{|c|c|c|c|c|}
\hline & $\begin{array}{c}\text { Group I } \\
\text { [Suture closure Group] } \\
(\mathrm{n}=150)\end{array}$ & $\begin{array}{c}\text { Group II } \\
\text { [Adhesive strip Group] } \\
(\mathrm{n}=150)\end{array}$ & $Z$ & $\mathbf{P}$ \\
\hline $\begin{array}{l}\text { Age (Years) } \\
\text { Range } \\
\text { Median (IQR) }\end{array}$ & $\begin{array}{c}18-38 \\
30(24-34.25)\end{array}$ & $\begin{array}{c}18-38 \\
28(22.75-32)\end{array}$ & -1.4 & $0.10 \mathrm{NS}$ \\
\hline $\begin{array}{c}\text { Gestation at Delivery (weeks) } \\
\text { Range } \\
\text { Median (IQR) }\end{array}$ & $\begin{array}{c}38-41 \\
39.5(38.7-40.3)\end{array}$ & $\begin{array}{c}38-41 \\
39.5(38.7-40.3)\end{array}$ & -0.3 & $0.70 \mathrm{NS}$ \\
\hline Number of cases with episiotomy & $94(62.7 \%)$ & $87(58 \%)$ & $\mathrm{X}^{2}$ & $\mathrm{P}$ \\
\hline Number of cases with $1^{\text {st }} \& 2^{\text {nd }}$ degree perineal tear & $56(37.3 \%)$ & $63(42 \%)$ & 0.8 & 0.40 \\
\hline
\end{tabular}

IQR interquartile range; Data presented as range, median (IQR). ${ }^{*}$ Analysis using Mann-Whitney’s U-Test for age and gestational age; NS non-significant. 
Table 2. Difference between interrupted suture closure and adhesive strip group regarding pain evaluation in the $1^{\text {st }}$ day after birth.

\begin{tabular}{|c|c|c|c|c|c|c|c|c|}
\hline Pain score & Group & No & Mild & Moderate & Severe & Very Severe Worst Pain & $\mathrm{X}^{2}$ & $\mathbf{P}$ \\
\hline \multirow{3}{*}{ Immediate } & Suture & $95(63.3 \%)$ & $55(36.7 \%)$ & - & - & - & \multirow{3}{*}{0.8} & \multirow{3}{*}{$0.30 \mathrm{NS}$} \\
\hline & & & & & & & & \\
\hline & Adhesive & $87(58 \%)$ & $63(42 \%)$ & - & - & - & & \\
\hline \multirow{2}{*}{2 hours } & Suture & $94(62.7 \%)$ & $56(37.3 \%)$ & - & - & - & \multirow{2}{*}{0.68} & \multirow{2}{*}{$0.40 \mathrm{NS}$} \\
\hline & Adhesive & $87(58 \%)$ & $63(42 \%)$ & - & - & - & & \\
\hline \multirow[b]{2}{*}{4 hours } & Suture & $49(32.7 \%)$ & $62(41.3 \%)$ & $39(26 \%)$ & - & - & \multirow[b]{2}{*}{6.12} & \multirow[b]{2}{*}{$0.04 \mathrm{~S}$} \\
\hline & Adhesive & $60(40 \%)$ & 68 (45.3\%) & $22(14.7 \%)$ & - & - & & \\
\hline \multirow[b]{2}{*}{6 hours } & Suture & 0 & $58(38.7 \%)$ & $83(55.3 \%)$ & $9(6 \%)$ & - & \multirow[b]{2}{*}{9.75} & \multirow[b]{2}{*}{$0.02 \mathrm{~S}$} \\
\hline & Adhesive & $2(1.3 \%)$ & $81(54 \%)$ & $60(40 \%)$ & $7(4.7 \%)$ & - & & \\
\hline 12 hours & Suture & - & $58(38.7 \%)$ & 79 (52.7\%) & $13(8.7 \%)$ & - & 3.74 & $0.10 \mathrm{NS}$ \\
\hline
\end{tabular}

Table 3. Difference between interrupted suture closure and adhesive strip group regarding pain evaluation during the $1^{\text {st }}$ week after birth.

\begin{tabular}{|c|c|c|c|c|c|c|c|c|c|}
\hline Pain score & Group & No & Mild & Moderate & Severe & Very Severe & Worst Pain & $\mathrm{X}^{2}$ & $\mathbf{P}$ \\
\hline \multirow[b]{2}{*}{ Day 1} & Suture & - & $42(28 \%)$ & $74(49.3 \%)$ & $34(22.7 \%)$ & - & & \multirow[b]{2}{*}{3.7} & \multirow[b]{2}{*}{$0.10 \mathrm{NS}$} \\
\hline & & & & & & & & & \\
\hline \multirow{3}{*}{ Day 2} & Suture & & $42(28 \%)$ & $76(50.7 \%)$ & $32(21.3 \%)$ & - & & \multirow{3}{*}{4.04} & \multirow{3}{*}{$0.10 \mathrm{NS}$} \\
\hline & & & & & & & & & \\
\hline & Adhesive & - & $58(38.7 \%)$ & $62(41.3 \%)$ & $30(20 \%)$ & - & & & \\
\hline \multirow[b]{2}{*}{ Day 3} & Suture & & $29(19.3 \%)$ & $45(30 \%)$ & 47 (31.3\%) & $29(19.3 \%)$ & & \multirow{2}{*}{15.2} & \multirow{2}{*}{$<0.01 \mathrm{HS}$} \\
\hline & Adhesive & - & $32(21.3 \%)$ & $67(44.7 \%)$ & $42(28 \%)$ & $9(6 \%)$ & & & \\
\hline \multirow{3}{*}{ Day 4} & Suture & - & $30(20 \%)$ & $55(36.7 \%)$ & $38(25.3 \%)$ & $25(16.7 \%)$ & $2(1.3 \%)$ & \multirow{3}{*}{18.4} & \multirow{3}{*}{$<0.01 \mathrm{HS}$} \\
\hline & & & & & & & & & \\
\hline & Adhesive & $1(0.7 \%)$ & $35(23.3 \%)$ & $81(54 \%)$ & $23(15.3 \%)$ & $10(6.7 \%)$ & - & & \\
\hline Day 5 & Adhesive & $4(2.7 \%)$ & $65(43.3 \%)$ & $61(40.7 \%)$ & $20(13.3 \%)$ & - & - & 14.01 & $<0.01 \mathrm{HS}$ \\
\hline \multirow{3}{*}{ Day 6} & Suture & $70(46.7 \%)$ & $74(49.3 \%)$ & $6(4 \%)$ & - & - & - & \multirow{3}{*}{2.8} & \multirow{3}{*}{$0.20 \mathrm{NS}$} \\
\hline & & & & & & & & & \\
\hline & Adhesive & $83(55.3 \%)$ & $64(42.7 \%)$ & $3(2 \%)$ & - & - & - & & \\
\hline Day 7 & Suture & 67 (44.7\%) & $72(48 \%)$ & $11(7.3 \%)$ & - & - & - & 14.5 & $<0.01 \mathrm{HS}$ \\
\hline
\end{tabular}

(equally distributed between both groups) asked for medical advice within the first seven days for pain, which was relieved by oral analgesics, but there were no cases of wound infection.

Table 4 shows difference between both groups during the second visit (7 - 10 days after birth) as regards sitting, walking, micturition and defecation, while Table 5 shows difference between both groups as regards the REEDA score during the second visit.

\section{Discussion}

The current study showed a significant difference in pain from 4 to 6 hours after 
Table 4. Difference between interrupted suture closure and adhesive strip group regarding pain evaluation in the $2^{\text {nd }}$ visit $(7-10$ days after birth).

\begin{tabular}{|c|c|c|c|c|c|c|c|c|c|}
\hline Pain score & Group & No & Mild & Moderate & Severe & Very Severe & Worst Pain & $\mathrm{X}^{2}$ & $\mathbf{P}$ \\
\hline \multirow[b]{2}{*}{ On sitting } & Suture & $44(29.3 \%)$ & $55(36.7 \%)$ & $51(34 \%)$ & - & - & - & \multirow[b]{2}{*}{1.04} & \multirow[b]{2}{*}{$0.50 \mathrm{NS}$} \\
\hline & Adhesive & $50(33.3 \%)$ & 47 (31.3\%) & $53(35.3 \%)$ & - & - & - & & \\
\hline \multirow{2}{*}{ On walking } & Suture & $43(28.7 \%)$ & $61(40.7 \%)$ & $46(30.7 \%)$ & - & - & - & \multirow[t]{2}{*}{1.45} & \multirow[t]{2}{*}{$0.40 \mathrm{NS}$} \\
\hline & Adhesive & $49(32.7 \%)$ & $51(34 \%)$ & $50(33.3 \%)$ & - & - & & & \\
\hline \multirow{2}{*}{ On micturition } & Suture & $56(37.4 \%)$ & $45(30 \%)$ & $49(32.7 \%)$ & - & - & - & \multirow{2}{*}{0.97} & \multirow{2}{*}{$0.61 \mathrm{NS}$} \\
\hline & Adhesive & $52(34.7 \%)$ & $53(35.3 \%)$ & $45(30 \%)$ & - & - & - & & \\
\hline On defecation & Suture & $56(37.3 \%)$ & $45(30 \%)$ & $49(32.7 \%)$ & - & - & - & 1.22 & $0.50 \mathrm{NS}$ \\
\hline
\end{tabular}

Table 5. REEDA score healing assessment in the $2^{\text {nd }}$ visit (7 to 10 days after birth).

\begin{tabular}{|c|c|c|c|c|c|c|}
\hline Score & Group & 0 & 1 & 2 & $\mathrm{X}^{2}$ & $\mathbf{P}$ \\
\hline \multirow{2}{*}{ Reddness } & Suture & $72(48 \%)$ & $78(52 \%)$ & - & \multirow{2}{*}{0.3} & \multirow{2}{*}{$0.50 \mathrm{NS}$} \\
\hline & Adhesive & 77 (51.3\%) & $73(48.7 \%)$ & & & \\
\hline \multirow[b]{2}{*}{ Oedema } & Suture & 145 (96.7\%) & $5(3.3 \%)$ & & \multirow{2}{*}{\multicolumn{2}{|c|}{$1 \mathrm{NS}$}} \\
\hline & Adhesive & 145 (96.7\%) & $5(3.3 \%)$ & & & \\
\hline \multirow{2}{*}{ Ecchymosis } & Suture & 149 (99.3\%) & $1(0.7 \%)$ & - & \multirow{2}{*}{ - } & \multirow{2}{*}{-} \\
\hline & Adhesive & $150(100 \%)$ & - & - & & \\
\hline \multirow{2}{*}{ Discharge } & Suture & 149 (99.3\%) & $1(0.7 \%)$ & - & & \\
\hline & Adhesive & $150(100 \%)$ & - & - & & \\
\hline \multirow{2}{*}{ Approximation } & Suture & $147(98 \%)$ & $3(2 \%)$ & - & \multirow{2}{*}{0} & \multirow{2}{*}{$1 \mathrm{NS}$} \\
\hline & Adhesive & $147(98 \%)$ & $3(2 \%)$ & - & & \\
\hline Total & Suture & $70(46.7 \%)$ & $72(48 \%)$ & $8(5.3 \%)$ & 1.38 & $0.40 \mathrm{NS}$ \\
\hline
\end{tabular}

birth in favor of the adhesive tape group, while there was insignificant difference between both groups in the first 2 hours which can be attributed to the effect of local anesthesia given before episiotomy. While there was insignificant difference between both groups in the time of skin closure, although the adhesive tape group had a wider time range, which may be attributed to more operators' experience in skin suturing.

There was a significant difference in pain in days 3, 4, 5 and 7 in favor of the adhesive tape group, which may be attributed to an exaggerated body response to the sutures characterized by predominance of macrophages at the third and fourth day to remove microbes and cellular debris, in addition to, enzymatic breakdown of the extracellular connective tissue matrix and elaboration of cytokines to stimulate angiogenesis and fibroplasias. Then at the fifth day fibroblasts secrete collagen, proteoglycans and elastin with a gradual shrinking in wound size, and the newly formed capillaries invade the wound with epithelial cells proliferation behind the wound edge and their migration across ground substance and collagen at the wound surface [13], although the second evaluation using the 
REEDA score showed insignificant differences between both groups, and there were no cases of wound infection in either group.

The current study had the advantages of having a high power (95\%) and of being double-blinded randomized controlled trial; however, the cases could see and feel difference in management. The main weak point of this study is the absence of long term follow-up after the second visit between seven and ten days after birth, and the use of pain which is a subjective measure as the only variable for patient's satisfaction; however, efforts were made to minimize this bias by explaining how to fill the follow up sheet.

Up to our knowledge the current study is the first to compare skin adhesive tape with the interrupted absorbable suture technique in episiotomy skin closure, yet other studies compared adhesive glue to sutures as [14] and [4], targeting a heterogeneous sample of primiparous and multiparous with a total number of 100 and 97 women respectively both supported the potential benefits of glue use, as a better alternative to sutures as regards procedure time and reduced pain sensation although there was insignificant difference between both groups at 7 and 30 days [14]. However, the cost of glue use may be an issue especially in a developing country with limited resources like Egypt, while [15] and [8] reported increase in pain sensation in the sutured arm when comparing skin adhesive tape to suturing the skin in surgeries other than obstetric.

Kinderberg et al. [16], compared interrupted, inverted stitches with continuous stitches for perineal repair and leaving the skin un-sutured, concluded that all three methods appear to be equivalent, there were no difference seen in perineal pain 10 days after birth using Visual Analogue Score and in wound healing evaluated by the REEDA scale at $24-48$ hours and 10 days postpartum and found the results similar in both groups, which is similar to the results of the REEDA score found in the current study.

Calculating the time of skin procedure only, decreased the bias of other delays, which may have happened and gave a precise idea about the real timing of the procedure; however, the main difficulty with application of the skin adhesive tape in the current study was keeping the wound dry, which was felt to cause a substantial loss of time with the procedure, this may be attributed to the nature of the perineum and the episiotomy process itself. However, other studies as [15] and [8] reported wound closure with adhesive tape to be easier and faster although the results were insignificant as compared to intracuticular suture closure after coronary artery bypass grafting; however, there was significantly less redness and edema in the adhesive tape group.

\section{Conclusion}

Skin adhesive tape may be superior to skin suturing in decreasing perineal pain after birth; however, further studies are needed to assess long-term effects, calculate costs and accurately measure patients' satisfaction, which were not addressed in this study. 


\section{Conflicts of Interest}

The authors declare no conflicts of interest regarding the publication of this paper.

\section{References}

[1] Ralph, W. and Frank, W. (2007) Episiotomy: Procedure and Repair Techniques. American College of Obstetricians and Gynecologists, Washington DC.

[2] DHS Egypt (2003) Egypt Interim Demographic and Health Survey. http://www.measuredhs.com/pubs/pub

[3] Saleh, W., Torky, H., Youssef, M., et al. (2018) Effect of Female Genital Cutting Performed by Health Care Professionals on Labor Complications in Egyptian Women: A Prospective Cohort Study. Journal of Perinatal Medicine, 46, 419-424. https://doi.org/10.1515/jpm-2016-0429

[4] Feigenberg, T., Maor-Sagie, E., Zivi, E., et al. (2014) Using Adhesive Glue to Repair First Degree Perineal Tears: Prospective Randomized Controlled Trial. BioMed Research International, 2014, Article ID: 526590. https://doi.org/10.1155/2014/526590

[5] Ma, W.-J., Zhou, Y., Mao, H., et al. (2014) Healing Time of Incision Infection after Hepatobiliary Surgery Treated by Needle-Free Incision Suture Closure. World Journal of Gastroenterology, 20, 815-819. https://doi.org/10.3748/wjg.v20.i42.15815

[6] Coulthard, P., Esposito, M., Worthington, H.V., van der Elst, M., van Waes, O.J.F. and Darcey, J. (2010) Tissue Adhesives for Closure of Surgical Incisions (Review). Cochrane Data Base Systemic Review, No. 5, CD004287.

https://doi.org/10.1002/14651858

[7] Ghosh, A., Nanjappa, M., Nagaraj, V. and Rajkumar, G.C. (2015) Comparison between Stainless Steel Staples and Silk Sutures for Primary Closure of Skin in Patients Undergoing Neck Dissection. Contemporary Clinical Dentistry, 6, 51-55. https://doi.org/10.4103/0976-237X.152938

[8] Lazar, H., McCann, J., Fitzgerald, A., et al. (2011) Adhesive Strips versus Subcuticular Suture for Median Sternotomy Wound Closure. Journal of Cardiac Surgery, 26, 344-347. https://doi.org/10.1111/j.1540-8191.2011.01257.x

[9] Royal College of Midwives (2012) Evidence Based Guidelines for Midwifery-Led Care in Labour: Suturing the Perineum.

[10] Beauvais, S. (2010) Practical Plastic Surgery for Nonsurgeons. Global Surgery and Anesthesia; Chapter 1. Suturing: The Basics. 1-20.

[11] Wong, D., Hackenberry, E., Wilson, D., Winkelstein, M.L. and Schwartz, P. (2001) Wong's Essentials of Pediatric Nursing. Elsevier, St. Louis, 1301.

[12] Reeda, D.N. (1974) Evaluating Postpartum Healing. Journal of Nurse-Midwifery, 19, 6-9.

[13] Simon, P.E., Meyers, A.D., Romo, T. III and Al Moutran, H. (2016) Skin Wound Healing. Medscape's References, Jan 20.

[14] Mota, R., Costa, F., Amaral, A., et al. (2009) Skin Adhesive versus Subcuticular Suture for Perineal Skin Repair after Episiotomy. Acta Obstetricia et Gynecologica, 88, 660-666. https://doi.org/10.1080/00016340902883133

[15] Van de Gevela, D., Soliman, M., Elenbaasa, T., et al. (2010) Is the Use of Steri-Strip for Wound Closure after Coronary Artery Bypass Grafting Better than Intracuticular Suture? Interactive Cardio Vascular and Thoracic Surgery, 10, 561-564. https://doi.org/10.1510/icvts.2009.222190 
[16] Kindberg, S., Stehouwer, M., Hvidman, L., et al. (2008) Postpartum Perineal Repair Performed by Midwives: A Randomised Trial Comparing Two Suture Techniques Leaving the Skin Unsutured. British Journal of Gynaecology, 115, 472-479.

https://doi.org/10.1111/j.1471-0528.2007.01637.x 